\title{
Participatory Framework Invoked by Processing-Motivated Filler Zhege ('This-CL') in Chinese Conversations:
} An Embodied Perspective

\author{
YANG Zhu \\ Southwest University, Chongqing, China
}

\begin{abstract}
This paper takes an embodied perspective to describe the participatory framework invoked by Chinese proximal demonstrative filler zhege ('this-CL') when it occurs as reaction to processing problems in spontaneous conversations. As a frequently-occurring filler, zhege conventionally marks a suspension of utterance delivery and signals speakers' effort of formulating a target unit while helping them hold the turn. Meanwhile, zhege invokes for conversational participants a framework of participation in the formulating effort-it specifies that speakers have epistemic access to the target unit while not specifying so for co-participants and thus invokes speakers' unilateral participation in producing the target unit. This format of participatory management is not only semantically shaped by the indexicality of zhege as a proximal demonstrative, but also constituted by the embodied cues of speakers when they produce zhege and engage in the formulating effort. Analyses of naturally-occurring Chinese conversations show that at these moments, speakers regularly display bodily cues characterized by self-orientation and detachment from co-participants, thus reinforcing their unilateral participation in the effort while making irrelevant or discounting the potential participation by co-participants. This participatory framework invoked by using filler zhege has particular relevance to turn holding in social interaction, and these findings may have implication for cross-linguistic studies of demonstrative fillers.
\end{abstract}

Keywords: filler, zhege, demonstrative, embodied cues, Chinese

\section{Introduction}

In spontaneous talk, a systematic and meaningful verbal byproduct is fillers. They generally arise from the processing problems in speech production and have some effect on speech comprehension. Demonstrative fillers, inter alia, are a particularly noticeable class of fillers, in that they not only reveal much about the psycholinguistic underpinnings of speech production, but also tend to specify a format of epistemic access to the delayed referent for conversational participants (Hayashi \& Yoon, 2006). Thus, demonstrative fillers can affect interactional participation in some unique patterns. In this paper, the author focuses on the occurrence of Chinese proximal demonstrative filler zhege ('this-CL') as motivated by processing problems and describes the participatory framework it invokes from an embodied perspective.

YANG Zhu, lecturer, Ph.D., School of Foreign Languages, Southwest University. 
Fillers that occur automatically as speakers' reaction to processing problems are usually understood as markers of delay, hesitation or disfluency, in contrast to fillers that result otherwise from speakers' deliberate manipulation for rhetorical or socio-interactional effects (Clark, 2006; Corley \& Stewart, 2008). The underlying assumption about reactive fillers is that speakers are inclined to monitor their production and cope with processing challenges. The sources of challenges pertain to various aspects of spontaneous production, mainly including speakers' uncertainty (Barr, 2001; Smith \& Clark, 1993), conceptualization of new information (Arnold, Fagnano, \& Tanenhaus, 2003), formulation of major, long or complex discourse units (Barr, 2001; Beattie, 1979; Boomer, 1965), lexical-retrieval or word-search difficulty (Brennan \& Williams, 1995; Schachter, Christenfeld, Ravina, \& Bilous, 1991; Levelt \& Cutler, 1983; Butterworth, 1979; Goldman-Eisler, 1968). These challenges are constantly present, posing trouble to on-line processing so that fillers as well as other hesitation phenomena may be anticipatable in spontaneous talk (Merlo \& Barbosa, 2010).

An immediate effect of fillers in face to face interaction is turn holding. As processing problems arise, utterance production is likely to be suspended. Using fillers can help speakers hold a turn by cueing to co-participants that they still desire to keep the floor and the current turn is still unfolding (Maclay \& Osgood, 1959; Ball, 1975; Schegloff, 1982; Clark \& Fox Tree, 2002). In effect, using fillers might run less risk of being interrupted than using silent pauses where there is suspension of utterance delivery (Sacks, Schegloff, \& Jefferson, 1974; Beattie, 1977).

Apart from facilitating turn holding while delivery is suspended as a result of processing problems, specific types of filler may simultaneously carry implications about certain aspects of the ongoing delay. For instance, English conventional fillers $u h$ and $u m$ are found to indicate the likely length of the delay projected by them- $u h$ is used to signal a minor delay while um a major one (Fox Tree, 2001; Clark \& Fox Tree, 2002). Demonstrative fillers are particularly noteworthy in this regard, in that they index participants' cognitive or epistemic relation with the delayed referent by virtue of their core indexical meaning. With such implications, the use of demonstrative fillers may have special effect on interactional management.

In what follows, drawing upon conversational data, the author documented the format of interactional participation in formulating the delayed referent specified by Chinese demonstrative filler zhege. The author first made a review of previous studies devoted to this specific topic, and then approached it otherwise from an embodied perspective.

\section{Filler Zhege in Conversations}

Chinese proximal demonstrative zhege (a spoken variant being zheige) is morphologically composed of zhe ('this') and neutral classifier $g e$ ('CL', literally meaning 'individual'), denoting the proximity and individuality of a referent, though the referent is not necessarily a singular entity (LÜ, 1999). Encoding proximal relations of a linguistic expression to aspects of context, zhege indexes deictic, tracking/anaphoric, discourse-deictic, and recognitional references, and allows both pronominal (as pronoun) and adnominal (as determiner or adjective) uses (cf. Himmelmann, 1996; Diessel, 1999; Lakoff, 1974).

In naturally occurring talk, zhege also frequently appears as a filler, marking a filled pause in the course of delivering what is due to be forthcoming and thus resulting in a delay of the target referent. Examples (1)-(2) are two illustrations (zhege in boldface for highlighting): 
Example (1) YS-SQQSDTBBY 05:12

((Health talk show guest ZHANG uses a simile.))

$1 \rightarrow$ ZHANG: Jiaru women-de jingmai shi changtong de, jiuxiang ${ }^{\mathbf{o}}$ zheige $^{\text {o:(.) }}(($ slightly gazes down))/e: If we.GEN channels are smooth ADJ, just.like ${ }^{\mathbf{0}}$ this- $\mathbf{C L}^{\mathbf{0}}$ : uh: xueye jiu.xiang qiche yiyang blood just.like auto one.look

'If our channels are smooth, just like ((hesitates)) blood (channels) and (roads for) auto'

Example (2) YST-XZYC 39:06

((Health talk show guest LI, facing the audience, cautions not to take seriously a preliminary idea of his.))

$1 \rightarrow$ LI: bu zu wei (0.4) zhege zhege dazhong-xing de xuanchuan not suffice for this-CL this-CL masses-mode MOD publicity '(that idea) does not suffice for ((hesitates)) massive publicity'

2 LIU:Mm.

In each instance above zhege is unambiguously reactive to a processing trouble. The speakers use it (prolonged and duplicated respectively) to fill a portion of the silence so as to hold the turn before figuring out the target unit. Here, zhege is neither part of the propositional content nor lexically integrated to a larger phrase.

Demonstratives, proximal and distal, are shown to be utilized as fillers in a wide range of regionally and typologically different languages (Amiridze, Davis, \& Maclagan, 2010; Hayashi \& Yoon, 2006; Diessel, 1999). Contrary to "empty" fillers like $e$ ('uh') and $m$ ('um'), demonstrative fillers are conventional lexical items that are semantically charged. They retain, albeit not in all instances, the core meaning of indexicality of standard demonstratives and thus can indicate the way they are used in relation to the delayed referent and the way they configure participants' cognitive state about the referent. This clearly holds true for Chinese proximal demonstrative filler zhege.

When motivated by problems in formulating a target utterance unit, filler zhege is categorized by Hayashi and Yoon (2006) into placeholder or interjective hesitator depending on its formal and semantic relations to the unit. A placeholder participates in the morpho-syntactic structure of utterances by functioning as a provisional proxy for a more specific and explicit referent which is sought for and is upcoming, and thus it is referential and directs attention to that referent. By contrast, an interjective hesitator is not a syntactic constituent and non-referential, occurring flexibly in utterances simply to indicate the emergence of production problems. Interjective hesitator demonstratives are an outcome of "pragmaticization", through which demonstratives have lost referentiality and syntactic participation and thus have become pragmatic markers to monitor utterance delivery, functioning much like the "interjection" fillers uh and um (Clark \& Fox Tree, 2002). A further criterion by which to distinguish a placeholder from an interjective hesitator is that the former foreshadows the morpho-syntactic and semantic categories of the sought-for element, while the latter entails no such congruence.

However, a distinction between placeholder and interjective hesitator in terms of referentiality, syntactic integration, and formal and semantic correspondence can hardly be maintained for filler zhege in a vast number of instances. Zhege has the potential to index reference to various types of referents (entities, attributes, events, etc.) and so it can represent multiple unit types and play versatile syntactic roles. A placeholder interpretation could in 
principle be applied to almost all uses as long as the delayed referent can be denoted by zhege. Granted so, it would become impractical to maintain a discrete distinction between placeholder zhege and interjective hesitator zhege on the above grounds, since it would be rather haphazard to decide on whether a filler zhege, de facto, occupies a syntactic slot and then refers to a certain utterance element that comes subsequently. Even in circumstances where zhege functions additionally to preface certain types of conversational move, as Hayashi and Yoon (2006) have contradicted themselves, it also "retains at least some degree of indexicality, i.e., the function of 'pointing' the hearer in the direction of subsequent action and designating it as the common focus of interaction” (p. 529). That is to say, referentiality is present in both placeholder and interjective hesitator demonstratives. Therefore, it is not well-grounded to draw a demarcation between placeholder and interjective hesitator zhege based on formal and functional characteristics.

Nevertheless, it appears certain that filler zhege, to a great extent, retains referentiality and then directs joint attention to the delayed element which speakers make effort to formulate. Previous studies, as mentioned above, have shown that fillers in general can direct listeners' attention to the upcoming unit. This could only be more so for zhege, in that demonstratives primarily function to point hearers' attention to referents in the universe of discourse (Diessel, 2006; Himmelmann, 1996). This attentional effect is explicitly shown in hearers' response as filler zhege occurs (optionally with attendant pauses and/or other fillers) - they tend to augment attention by granting (augmented) gaze to speakers. Since filler zhege has potential reference to and can direct attention to a more specific element made available subsequently, it is sometimes also seen as an initiator of self-repair, as is the case with some other demonstrative fillers (Fox, Hayashi, \& Jasperson, 1996).

Besides, filler zhege also projects a configuration of participants' cognitive state about the referent. It is proposed by many that by using zhege speakers display cognitive access to the referent yet without specifying whether hearers have such access, while by using the distal nage ('that-CL') they invoke shared access or remote access (Hayashi \& Yoon, 2006; FANG, 2002; TAO, 1999; HUANG, 1999). Semantic studies have shown that proximal demonstratives designate the referent to be in close proximity, spatio-temporal, psychological or cognitive, to the deictic center (viz. the speaker) (Lyons, 1977; Fillmore, 1997). There is also a suggestion that an overall discourse function of proximal demonstratives is to index proximity, especially cognitive proximity (Averintseva-Klisch \& Consten, 2007; Consten \& Averintseva-Klisch, 2012). When using zhege as a filler in cases of processing problems, speakers leave an implication that the delayed referent, whether discourse-old or discourse-new, is what they know or familiar with (whether it is so for hearers is unspecified). Not unexpectedly, zhege is also labeled by some as a pre-positioned topic marker, which packages the following referent, old or new, as within speakers' epistemic sphere (FANG, 2002; LIU, 2009). This observation is reflected in some positive sociolinguistic correlations between the frequency of using zhege and speakers' degree of socialization and power (GUO, 2009; WANG, 2013), suggesting that more highly socialized and powerful speakers might signal greater proximity to entities within the universe of discourse.

Specifying that speakers have cognitive access/proximity to the sought-for referent but without specifying that listeners do so, filler zhege affects the organization of interaction in two ways. On the one hand, zhege indicates that the processing problem occurs at the "formulating” stage (see Levelt, 1993), in line with HUANG's (1999) observation from a corpus analysis and Hayashi and Yoon's (2006) observation. Comparably, Gaby (2004) has found in Thaayorre language that the proximal demonstrative filler inhul ('this one') indicates a minor 
retrieval difficulty while the distal yuunhul ('that one') a major one. On the other hand, zhege invokes no invitation of participation by the hearer in the process of coping with the production problem, even though the hearer may volunteer collaborative participation (Hayashi \& Yoon, 2006).

To complement purely semantic analyses, this paper takes an embodied perspective to examine this format of participants' epistemic access to the delayed referent specified by filler zhege and the attendant effect on managing participants' differential participation in the formulating process. The author will show how this format and interactional effect are reflected in speakers' embodied cues.

\section{Data}

The data consist of naturally-occurring spontaneous conversations in which interlocutors are mutually present. They include video-taped episodes of TV talk show and interview program concerning health, economy, education and current affairs. They are collected from openly available online sources. Some of these conversations are dyadic with audiences present, some are triadic with audiences present, some are dyadic without audiences, and some are triadic without audiences. In view of the fact that the analyses in this study involve examining the accompanying embodied cues of speakers, it is justified that audio-only conversations are not included in the data.

The transcription of the original data is based on Chinese Pinyin Scheme (Mandarin phonetic transcription), with annotations of some relevant paralinguistic and non-verbal features. Tokens of zhege as filler (rather than standard demonstrative) are marked in boldface. Responses in which the verbal modality consists merely of particles resembling English response tokens such as $u h$ and um are presented only as a single line of their English counterparts. The transcription symbols and glossing abbreviations are listed in Appendices A and B. Two excerpts of the transcribed conversations have already been shown in the above.

\section{Embodied Cues of Participatory Framework}

A normative expectation in interaction is that conversational participants display mutual attention so as to establish interactional coordination (Kendon, 1967; C. Goodwin, 1981; Vertegaal, Slagter, van der Veer, \& Nijholt, 2001). They do so most explicitly by showing gaze to one another. While using zhege in response to processing difficulty like formulation trouble, speakers tend to employ a different pattern of attention allocation and gaze shape characterized by self-orientation and detachment from co-participants. The import of this embodied practice is an effort of production on the one hand and a signal of speakers' specification of participants' differential participation in the effort on the other.

\section{Making Irrelevant Co-participants’ Access and Participation}

In the data, where filler zhege arises as a reaction to processing difficulty, speakers are inclined to simultaneously or subsequently withdraw their gaze from the current recipient and then, upon the possible completion of formulating, return their gaze to the recipient or in some circumstances to the video cam, optionally making accompanying head movements. This contour of gaze withdrawal and return amounts to a "thinking" gesture, consistent with the findings by Beattie (1979), M. H. Goodwin and C. Goodwin (1986), Heylen (2006), etc.. It has been observed that speakers look away from the recipient while dealing with processing trouble to concentrate attention, avoid distraction and forestall responses (Kendon, 1967; Argyle, 
Ingham, Alkema, \& McCallin, 1973; Argyle \& Cook, 1976). Furthermore, doing so makes irrelevant co-participants' access to the target referent and potential participation in the formulating effort.

One common shape of speaker gaze withdrawal is a leftward gaze-off. In Example (3), while YANG has previously been gazing at his interlocutors, he uses zhege (sounding as zhei ge $e^{o}$ ) (line 1) when planning the upcoming clausal unit and then immediately gazes off left during a pause. Upon the possible completion of the planning, he returns gaze to them and resumes the utterance delivery.

Example (3) YST-PDSBQ2 05:25

((Health talk show guest YANG describes what a video clip has just shown.))

$1 \rightarrow$ YANG: Gangcai zhege da pingmu shuo.le zhei ge $^{\boldsymbol{o}}() /.(($ slightly turns gaze off left, returns gaze)) Just.now this-CL big screen say.PST this- ${ }^{\circ} \mathbf{C L}^{\mathbf{0}}$

2 yong zhongchengyao lai paidu zhan.le shi diyi wei de use Chinese.patent.drug to expel.toxin take.PST is first position DC

'The screen just showed ((hesitates)) using Chinese patent drug ranks the top toxin-expulsion method'

Similarly in Example (4), subsequent to a video-clip show hostess TIAN initiates with zhege a resumptive sequence and later uses zhege again during a word-search effort. Here, TIAN has maintained gaze at ZHANG from the outset of the sequence through the initiating zhege until she produces the word-search zhege. At this hesitation point, she instantly gazes off leftward and then back to ZHANG within a 0.6-second pause (line 1) before finally articulating the target word fangshi ('mode') (line 2).

Example (4) YS-SQQSDTBBY 03:01

$1 \rightarrow$ TIAN: $\quad$ Zheige (.) chuli zhege touteng-touyun $\quad$ de: $\quad$ zheige (0.6)/((gazes off left and back))

This-CL treat this-CL headache-dizziness MOD: this-CL

2 fangshi ye shi wuhua-bamen de

mode also is various DC

'((hesitates)) treating headache \& dizziness employs various ((hesitates)) modes'

3 ZHANG: ((nods)) $M m$

A leftward gaze-off as such is a common itinerary of gaze withdrawal found in the data. By temporarily removing gaze from the recipient, speakers devote attention to their unilateral formulating effort and meanwhile make irrelevant interlocutors' access to the sought-for element and potential participation in the effort.

Yet the most common itinerary of gaze withdrawal found in the data is a down-left tilt of gaze. Gaze tilt is likely to co-occur with head tilt, and these movements of speakers are typical indicators of thinking or processing when the turn is still unfolding (Ishi, Ishiguro, \& Hagita, 2014) (see Example (5)). Guest JIA has been switching gaze between different recipients (hostess YUE and the audience), and at the beginning of this sequence his gaze is maintained at the audience.

Example (5) YST-YSZJSLF 11:04

$1 \rightarrow$ JIA: Hai you yixie jiduan de (0.6) bijiao (.) zhei ze $^{o}:::$ (0.4)/((tilts gaze slightly down left)) Still have some extreme ADJ relatively this- ${ }^{\circ} \mathbf{C L}^{\mathbf{0}}:::$

dajia/((gazes back at audience)) tingqilai dou juede((gazes at Y))bukesiyi [de kesou everyone sound all feel inconceivable ADJ cough 
'There still are some extreme cough cases, relatively ((hesitates)) sounds inconceivable to everyone’

3 YUE:

$[\mathrm{Mm}$

As difficulty arises in searching for an adjectival element projected by the foregoing structure and especially the preceding adverb bijiao ('relatively') (line 1), JIA's attention is directed to the unilateral searching effort, shown by the 0.4-second slight down-left tilt of gaze following the prolonged filler zhege (sounding as zhei ${ }^{\circ} e^{o}$ ). Upon resuming the delivery of a repair that is to introduce the target adjectival element bukesiyi ('inconceivable'), he simultaneously returns gaze to the recipients, first to the audience and then to hostess YUE (line 2).

Another characteristic example of down-left gaze tilt is Example (6), in which hostess YUE encounters trouble in formulating a nominal element (line 1). She first uses zhege in the slot of the nominal, and then devotes a pause to planning the element, which involves an attentional shift signaled by the half-closure of eyes and the down-left gaze tilt.

Example (6) YST-YSZJSLF 08:16

$1 \rightarrow$ YUE: ((faces audience)) ranhou a genju ta zhege kousou-de zhege (.) (0.8)/((half-closes eyes, then PRT according he this-CL cough.GEN this-CL

$2 \rightarrow \quad$ looks slightly down left)) shijian/((starts to face up)).de changduan ((gazes back at audience)) time.GEN length

3 lai panduan daodi shi shenti-de shenme buwei yinfa de zheyang de kesou to judge on.earth is body.GEN what part cause MOD such MOD cough 'then according to one's cough's ((hesitation)) duration judge what body part on earth is the cause'

$4 \quad$ ((continues))

Speakers are also found to withdraw gaze from the current recipient by turning gaze straight down, which is usually accompanied by eyes-narrowing and/or a slight bend-down of head. In Example (1), there is such a token. Here Example (1) is reproduced as Example (7). As ZHANG is searching for a word so as to establish a simile, she looks away from the current hearers by slightly gazing down, pursuing a unilateral effort in figuring out a target word.

Example (7) YS-SQQSDTBBY 05:12

((Health talk show guest ZHANG uses a simile.))

$1 \rightarrow$ ZHANG: Jiaru women-de jingmai shi changtong de, jiu xiang ${ }^{\mathbf{z}}$ zheige $^{\boldsymbol{o}}:($.$) ((slightly gazes down))/e:$ If we.GEN channels are smooth ADJ, just like ${ }^{\mathbf{0}}$ this- $\mathbf{C L}^{\mathbf{0}}$ : uh:

$2 \quad$ xueye jiu xiang qiche yiyang blood just like auto one.look

'If our channels are smooth, just like ((hesitates)) blood (channels) and (roads for) auto'

Again, in Example (8) ZHANG, sitting face to face with the audience, converses with two different interlocutors TIAN and CHEN, who sit to her front left and front right respectively. While switching her gaze from TIAN to CHEN, ZHANG suspends the movement in mid-course at a point of retrieval problem signaled by filler zhege. Subsequently, she engages further attention in the retrieval effort by narrowing eyes and 
slightly bending head down, until she succeeds in producing the target qvtengpian ('painkiller') and simultaneously gazes up to CHEN.

Example (8) YST-SQQSDTBBY 03:21

1 ZHANG: ((starts to gaze off $\mathrm{T})$ ) guasha zhiliao touteng ne ((gazes at cam)) gen zhege skin.scraping treat headache TP with this-CL

$2 \rightarrow \quad$ ((narrows eyes, bends slightly down)) qvtengpian/((gazes up to Ch)) hai you qvbie painkiller still have distinction

'(using) skin-scraping to treat headache is different from ((hesitates)) (using) painkiller’

\section{CHEN: $M m$}

In some instances, gaze withdrawals are accompanied with gesticulation characterized by an up-and-down movement or roll of hand(s). Gesticulation is found to facilitate lexical retrieval in contexts of processing difficulty (Butterworth \& Hadar, 1989; Hadar \& Butterworth, 1997; Hadar, Wenkert-Olenik, Krauss, \& Soroker, 1998; Krauss \& Hadar, 1999). A case in point is Example (9), where gesticulation is part of the speaker's word-search effort (line 2), alongside the gaze withdrawal and downward head movement.

Example (9) QQSRX-2014011807:25

1 DOU: ((gazes rightward at $\mathrm{X})$ ) Zhege ren la zhe hen you yisi, yao rang wo (.) jiao wo shuo ha This-CL person TP this very have fun, if let me ask me say PRT

$2 \rightarrow \quad$ ta ye suan shi zhege: $\quad e:($.$) ((withdraws gaze, turns head straight downward and gesticulates))$ he also count is this-CL: uh:

3 jiushi ((starts to gaze up and to turn head back to X)) zhiwu-zhi-bian namely post.GEN-convenience

'This guy is funny, I'd say (his conduct) counts as (abusing) the convenience of his post'

In addition, some other forms of gaze withdrawal from recipients following or accompanying filler zhege are also found in the data, including simply narrowing eyes, rolling eyes, and squinting. They all, like the previous forms, indicate that speakers are engaged in the unilateral formulating effort and attempt to forestall co-participants' response. Such embodied cues reinforce the impression that co-participants' epistemic state about the target referent is irrelevant and they are not invited into the seeking effort.

Recipients, as the data show, tend not to chime in while the current speaker is engaged in the post-zhege formulation effort, except that they might provide back-channel cues like $\mathrm{mm}$ as a response to speaker's finally successful delivery of the target unit. This is in line with the observation that co-participants' epistemic access is unspecified and their participation during the process is made irrelevant.

\section{Discounting Co-participants' Access and Participation}

In cases where recipients actually volunteer collaborative participation in formulating the referent, the speaker tends still to uphold his autonomy of access to the referent (Hayashi \& Yoon, 2006). Doing so can in effect discount recipients' access and co-participation while reinforcing the speaker's unilateral engagement. One such example is in (10).

Example (10) YST-XZYC 22:09

((LI, with hostess LIU, refers to the abidance of doctor's advice.)) 
1 LI: Suoyi ni-de xun-yi-xing (.) women yisheng jiaozuo xun-yi-xing

So you.GEN follow-doctor-quality we doctors call follow-doctor-quality

'So one's doctor's-advice-abidance, we doctors call so,'

2 LIU:Mm

$3 \rightarrow$ LI: jiushi ni zunxun yizhu de zhezhong zhege(0.5)/((gazes off leftward and back)) namely you follow doctor's-advice MOD this-kind this-CL

$4 \rightarrow \quad>^{o}$ zhege $^{o o}$ zhege $^{o}<[($ shiyi- $)$

$>^{\mathbf{0}}$ this- $\mathbf{C L}^{\mathbf{0}}$ this- $\mathbf{C} \mathbf{L}^{\mathbf{0}}<$ (proper-)

'namely one's ((hesitates)) of following doctor's advice'

$5 \rightarrow$ LIU: $\quad$ [luoshi chengdu=

implement degree=

'implementation degree'

6 LI: =a a a luoshi chengdu, jiu he zhongyang-de haozhao yiyang, luoshi chengdu bu hao =oh oh oh implement degree, just with central.GEN call same, implement degree not good 'oh, implementation degree, just like the Party Central Committee's call, (it) is not well implemented.'

LI has been searching for a nominal unit projected by the utterance-so-far (lines 3-4). He suspends the delivery with zhege and then gazes off leftward to devote attention to the formulating effort (line 3). Upon possible completion, he gazes back and goes on to deliver the target unit prefaced by two tonally weakened and rushed zheges (line 4). Overlapping the target unit, LIU proffers a candidate nominal (line 5). However, in response (line 6), LI structurally latches Liu's utterance and his own, uses a triplicate of interjection $a$ ('oh') as a preface to a repeat of the nominal, and then pursues a first assertion on that referent. The latter two practices, in particular, are recognized as methods to uphold an independent epistemic position as regards the referent (Heritage, 2002; Heritage \& Raymond, 2005). Liu’s volunteered access and participation are thence severely discounted. A comparable example is found in (11):

\section{Example (11) SINA.EDU-LXJYFCC 05:47}

(((Hostess MA of web media platform Sina Education interviews CHEN (vice-President of child education institution Langxun Education), who has on behalf of Langxun Education just received an award from Sina. MA and CHEN sit side by side facing the cam. Here CHEN assesses the importance of Langxun's strategic cooperation with some global education publishers.))

1 CHEN: [((Faces cam)) Buguan buguan shi duiyu women [hezuo huoban laijiang [hai shi duiyu No.matter no.matter is for our cooperation partner TP or is for 'Whether for our partners or for'

2 MA: [((Faces Chen)) $[($ turns to cam))

$[\mathrm{Mm}$

3 CHEN: women-de zhege guangda de zhe zhong e::(0.8) zheige ((rolls eyes: onset))/zheige:: we.GEN this-CL vast ADJ this kind uh:: this-CL this-CL:: [(0.3) e: (0.4) ((rolls eyes: coda)) [(shao-) $\quad[>\underline{A}<$ xuesheng xuesheng pengyou laijiang ha uh: $\quad(\mathrm{ki}-) \quad>\underline{\mathrm{OH}}<$ student student friend $\mathrm{TP}$ FP 'this kind of our vast ki-, oh, students, student friends' 
$5 \rightarrow$ MA: $\quad[(($ gazes at Chen $))$

'students, child friends, mm'

[xuesheng [shao'er pengyou-men, $\mathrm{mm}$ ((turns to cam))

student child friend-PL $\mathrm{mm}$

6

$\mathrm{Mm}$

7 CHEN: dou you zheige: (.) [(0.4)hen da de yiyi [(zhongyao)-de yiyi [(zheyang)

all have this-CL: $\quad$ very big ADJ meaning (important).ADJ meaning (such)

'((it)) means quite a lot to all'

8 MA:

$[($ gazes at Chen $))$

$[(($ nods $))$

[Shi de

Yes DC

'Yes'

In lines 3-4, CHEN encounters difficulty in searching for a word to denote those young learners who receive training from the institution he is on behalf of. During the word-search process, CHEN maintains his face toward the cam and rolls eyes, without casting a look at MA. In this way, CHEN makes irrelevant MA's epistemic state and forestalls MA's potential interruption and co-participation in the search. However, MA turns to gaze at CHEN (line 5) as CHEN'S hiatus has reached the end of a duplicated zhege (line 4), registering directed attention to the pending element. As CHEN's hesitation still continues and the searched-for word is not yet forthcoming, MA then supplies some candidate words for Chen (line 5), which happens to overlap CHEN's resumption. CHEN recycles the first candidate word xuesheng ('student'), yet prefacing it with rushed interjection $A$ (' $\mathrm{OH}$ '), which indicates that this word is in his repertoire but has just eluded him (cf. Heritage, 2002). Moreover, CHEN subsequently revises the word xuesheng ('student') into xuesheng pengyou ('student friend'), as a token of defending his epistemic independence as regards the referent, thus openly discounting MA's co-participation.

So far in this section, some examples are taken to describe speakers' embodied cues while they use filler zhege as reaction to processing problems. At these moments, speakers tend to shift their attention from co-participants to the processing effort so as to formulate the target element, usually by displaying gaze withdrawal and optionally head movements. These self-oriented cues of speakers reflect the epistemic and participatory framework specified by processing-motivated filler zhege: Speakers have access to the target unit and are engaged in formulating the unit, while co-participants' access and co-participation in this regard are irrelevant or discountable.

\section{Discussion and Conclusions}

In the above the regular embodied cues of speakers are examined when filler zhege arises as motivated by processing problems during spontaneous production. These cues take a patterned form: speakers first use filler zhege (sometimes duplicated or prolonged), and then subsequently devote attention to the processing effort by withdrawing gaze from or granting no gaze to recipients during an ensuing silent pause, optionally making other concomitant gestural cues indicating attentional detachment from recipients. These cues are oriented to the format of epistemic access and participation specified by zhege. Zhege packages the delayed unit as a referent epistemically accessible/proximal to speakers, yet not specifying so to hearers. By this epistemic token, filler zhege configures a pattern of differential participation by interactants in the formulating process. 
By projecting the cognitive availability of the delayed referent, zhege signals the definiteness of the referent and combats an implication of conceptual difficulty. Employing the concomitant embodied cues that show a momentary attentional detachment from the co-participants and a devotion to unilateral effort in the formulation can help speakers secure holding the turn, though not guaranteeing it. As has been suggested by Kendon (1967) and C. Goodwin (1981), speakers' attention to and gaze at co-participants not only signal addresseehood to them, but more pertinently attend to their co-participation in the joint activity and expect their response. A good case in point is where back-channeling is expected, speakers tend to gaze at recipients to invite them to offer some cues to collaborate in the current turn construction (Bavelas, Coates, \& Johnson, 2002). Thus, not granting gaze to or removing gaze from the recipients during word search process implies the absence of expectation of recipients' contribution at that very moment. Using these embodied cues alongside zhege, speakers work to forestall recipients' "premature" response or even collaborative interruption. Furthermore, this embodied practice also reinforces speakers' access to the target referent as specified by zhege and discounts the relevance of recipients' access.

Processing-motivated filler zhege is revealing about the psycholinguistic and cognitive mechanisms of speech production, yet it simultaneously invokes an interactional framework for participants. Exploitation of zhege as a filler has a particularly noticeable role to play in helping speakers hold the turn as the turn-unfolding is momentarily suspended. This sui generis feature of filler zhege is traceable to the epistemics specified by the core indexical meaning of zhege as a standard proximal demonstrative.

As outlined above, demonstratives, proximal and distal, are a noticeable source of fillers in a wide range of languages. They differ from the conventional "empty" fillers in that they carry the essential indexicality and point to the upcoming target unit. With this semantic quality, demonstrative fillers have the potential to integrate themselves into the morpho-syntactic structure of utterance and can combat a sense of disfluency. It is precisely this characteristic that underlies demonstrative fillers as potentially effective turn-holders where processing problems result in the suspension of delivery. Proximal demonstrative fillers, in particular, index cognitive proximity and suggest speakers' knowingness as regards the delayed referent, so they could diminish any implication of delivery resumption difficulty. Chinese proximal demonstrative filler zhege cues this information, while "empty” fillers do not carry such epistemic cues and the distal nage ('that-CL') may imply remote access and indeed is less often used as filler (HUANG, 1999). By virtue of this signal, zhege invokes speakers' epistemic access to the sought-for target and a framework in which speakers seek for the target unilaterally.

When utterance delivery runs into potential disruption, there is still a preference for within-turn progressivity, as is the case with word searches (Schegloff, 1979; Stivers, 2006). The competence in holding the turn during word searching process is a fundamental aspect of the competence of social actors in interaction. This type of competence is constantly monitored and displayed by them in turn construction, as conversational turns are sought and valued in the give-and-take of interaction (Sacks, et al., 1974). Interactional participants orient to their own image as a competent contributor to the communication event. As Goffman (1967) put,

In general, then, a person determines how he ought to conduct himself during an occasion of talk by testing the potentially symbolic meaning of his acts against the self-images that are being sustained. In doing this, however, he incidentally subjects his behavior to the expressive order that prevails and contributes to the orderly flow of messages. (pp. 38-39)

Progressive presentation of information is crucial for the maintenance of the image as a competent social actor. 
Moreover, embodied cues carry essential clues about the import of utterances. A more comprehensive examination of the use of verbal expressions can be informed by a wider perspective that takes into account multiple modalities. Lastly, the findings in this study may have implication for cross-linguistic examinations of the use of proximal demonstrative fillers that are motivated by processing problems. To what extent proximal demonstrative fillers in other languages invoke the same participatory framework as zhege does demands further inquiry.

\section{References}

Amiridze, N., Davis, B. H., \& Maclagan, M. (Eds.). (2010). Fillers, pauses and placeholders. Amsterdam: John Benjamins Publishing. Argyle, M., \& Cook, M. (1976). Gaze and mutual gaze. Cambridge: Cambridge University Press.

Argyle, M., Ingham, R., Alkema, F., \& McCallin, M. (1973). The different functions of gaze. Semiotica, 7(1), 19-32.

Arnold, J. E., Fagnano, M., \& Tanenhaus, M. K. (2003). Disfluencies signal theee, um, new information. Journal of Psycholinguistic Research, 32(1), 25-36.

Averintseva-Klisch, M., \& Consten, M. (2007). The role of discourse topic and proximity for demonstratives in German and Russian. Special Issue of Language in Contrast, 7(2), 219-240.

Ball, P. (1975). Listener's responses to filled pauses in relation to floor apportionment. British Journal of Social \& Clinical Psychology, 14, 423-424.

Barr, D. J. (2001). Trouble in mind: Paralinguistic indices of effort and uncertainty in communication. In C. Cavé, I. Guaïtella, \& S. Santi (Eds.), Oralité et gestualité: Interactions et comportements multimodaux dans la communication (Orality and gestuality. Interaction and multimodal behavior in communication) (pp. 597-600). Paris: L'Harmattan.

Bavelas, J. B., Coates, L., \& Johnson, T. (2002). Listener responses as a collaborative process: The role of gaze. Journal of Communication, 9, 566-580.

Beattie, G. W. (1977). The dynamics of interruption and the filled pause. British Journal of Social \& Clinical Psychology, 16, 283-284.

Beattie, G. W. (1979). Planning units in spontaneous speech: Some evidence from hesitation in speech and speaker gaze direction in conversation. Linguistics, 17(1-2), 61-78.

Boomer, D. S. (1965). Hesitation and grammatical encoding. Language and Speech, 8(3), 148-158.

Brennan, S. E., \& Williams, M. (1995). The feeling of another's knowing: Prosody and filled pauses as cues to listeners about the metacognitive states of speakers. Journal of Memory and Language, 34, 383-398.

Butterworth, B. (1979). Hesitation and the production of verbal paraphasias and neologisms in jargon aphasia. Brain and Language, 18, 133-161.

Butterworth, B., \& Hadar, U. (1989). Gesture, speech and computational stages. Psychological Review, 96, 168-174.

Clark, H. H. (2006). Pauses and hesitations: Psycholinguistic approach. In K. Brown (Ed.), Encyclopedia of language and linguistics (pp. 244-248 ). Amsterdam: Elsevier.

Clark, H. H., \& Fox Tree, J. E. (2002). Using uh and um in spontaneous speaking. Cognition, 84, 73-111.

Consten, M., \& Averintseva-Klisch, M. (2012). Tentative reference acts? "Recognitional demonstratives” as means of suggesting mutual knowledge-Or overriding a lack of it. Research in Language, 10(3), 257-277.

Corley, M., \& Stewart, O. W. (2008). Hesitation disfluencies in spontaneous speech: The meaning of um. Language and Linguistics Compass, 2, 589-602.

Diessel, H. (1999). Demonstratives: Form, function and grammaticalization. Amsterdam: John Benjamins.

Diessel, H. (2006). Demonstratives. In K. Brown (Ed.), Encyclopedia of language and linguistics (pp. 430-435). Amsterdam: Elsevier.

FANG, M. (2002). On the grammaticalization of zhe in Beijing Mandarin: From demonstrative to definite article. Zhongguo Yuwen (Studies of the Chinese Language), 4, 343-356, 382-383.

Fillmore, C. J. (1997). Lectures on deixis. Stanford: Center for the Study of Language and Information (CSLI) Publications.

Fox Tree, J. E. (2001). Listeners' uses of um and uh in speech comprehension. Memory \& Cognition, 29(2), 320-326.

Fox, B. A., Hayashi, M., \& Jasperson, R. (1996). Resources and repair: A cross-linguistic study of syntax and repair. In E. Ochs, E. A. Schegloff, \& S. A. Thompson (Eds.), Interaction and grammar (pp. 185-237). Cambridge: Cambridge University Press.

Gaby, A. (2004). Out of sight and out of mind: Distance and the use of Thaayorre demonstrative "fillers". Annual Conference of the Australian Linguistics Society (ALS), Sydney. 
Goffman, E. (1967). On face-work. Interaction ritual. New York: Doubleday.

Goldman-Eisler, F. (1968). Psycholinguistics: Experiments in spontaneous speech. London: Academic Press.

Goodwin, C. (1981). Conversational organization: Interaction between speakers and hearers. New York: Academic Press.

Goodwin, M. H., \& Goodwin, C. (1986). Gesture and coparticipation in the activity of searching for a word. Semiotica, 62(1/2), 51-75.

GUO, F. L. (2009). A sociolinguistic analysis of discourse markers zheige and neige in Beijing vernacular. Zhongguo Yuwen (Studies of the Chinese Language), 5, 429-437/480.

Hadar, U., \& Butterworth, B. (1997). Iconic gesture, imagery and word retrieval in speech. Semiotica, 15, 147-172.

Hadar, U., Wenkert-Olenik, D., Krauss, R. M., \& Soroker, N. (1998). Gesture and the processing of speech: Neuropsychological evidence. Brain and Language, 62(1), 107-126.

Hayashi, M., \& Yoon, K-E. (2006). A cross-linguistic exploration of demonstratives in interaction: With particular reference to the context of word-formulation trouble. Studies in Language, 30(3), 485-540.

Heritage, J. (2002). Oh-prefaced responses to assessments: A method of modifying agreement/disagreement. In C. Ford, B. A. Fox, \& S. Thompson (Eds.), The Language of turn and sequence (pp. 196-224). Oxford: Oxford University Press.

Heritage, J., \& Raymond, G. (2005). The terms of agreement: Indexing epistemic authority and subordination in talk-in-interaction. Social Psychology Quarterly, 68(1), 15-38.

Heylen, D. (2006). Head gestures, gaze and the principles of conversational structure. International Journal of Humanoid Robotics, 3(3), 1-27.

Himmelmann, N. P. (1996). Demonstratives in narrative discourse: A taxonomy of universal uses. Studies in Anaphora, 33, $205-254$.

HUANG, S. F. (1999). The emergence of a grammatical category definite article in spoken Chinese. Journal of Pragmatics, 31 , 77-94.

Ishi, C. T., Ishiguro, H., \& Hagita, N. (2014). Analysis of relationship between head motion events and speech in dialogue conversations. Speech Communication, 57, 233-243.

Kendon, A. (1967). Some functions of gaze-direction in social interaction. Acta Psychologica, 26, 22-63.

Krauss, R. M., \& Hadar, U. (1999). The role of speech-related arm/hand gestures in word retrieval. In L. S. Messing \& R. Campbel (Eds.), Gesture, speech and sign (pp. 93-116). Oxford: Oxford University Press.

Lakoff, R. (1974). Remarks on "this” and “that”. In M. Lagaly, R. Fox, \& A. Bruck (Eds.), Papers from the 10th Regional Meeting of the Chicago Linguistics Society (pp. 345-356 ), the University of Chicago.

Levelt, W. J. M. (1993). Speaking: From intention to articulation. Cambridge, MA: The MIT Press.

Levelt, W. J. M., \& Cutler, A. (1983). Prosodic marking in speech repair. Journal of semantics, 2(2), 205-218.

LIU, L. Y. (2009). “Zhege” and “nage” as discourse markers. Yuyan Jiaoxue Yu Yanjiu (Language Teaching and Research), 1, $89-96$.

LÜ, S. X. (1999). Xiandai hanyu babai ci (Eight hundred modern Chinese words). Beijing: The Commercial Press.

Lyons, J. (1977). Semantics. Cambridge: Cambridge University Press.

Maclay, H., \& Osgood, C. (1959). Hesitation phenomena in spontaneous English speech. Word, 15(1), 19-44.

Merlo, S., \& Barbosa, P. A. (2010). Hesitation phenomena: A dynamical perspective. Cognitive Processing, 11(3), $251-261$.

Sacks, H., Schegloff, E. A., \& Jefferson, G. (1974). A simplest systematics for the organization of turn-taking in conversation. Language, 50, 696-735.

Schachter, S., Christenfeld, N., Ravina, B., \& Bilous, F. (1991). Speech disfluency and the structure of knowledge. Journal of Personality and Social Psychology, 60(3), 362-367.

Schegloff, E. A. (1979). The relevance of repair for syntax-for-conversation. In T. Givon (Ed.), Syntax and semantics 12: Discourse and syntax (pp. 261-88). New York: Academic Press.

Schegloff, E. A. (1982). Discourse as an interactional achievement: Some uses of "uh huh" and other things that come between sentences. In D. Tannen (Ed.), Analyzing discourse: Text and talk. Georgetown University roundtable on languages and linguistics 1981 (pp. 71-93). Washington, DC: Georgetown University Press.

Smith, V. L., \& Clark, H. H. (1993). On the course of answering questions. Journal of Memory and Language, 32, 25-38.

Stivers, T. (2006). A preference for progressivity in interaction. Language in Society, 35(3), 367-392.

TAO, H. Y. (1999). The grammar of demonstratives in Mandarin conversational discourse: A case study. Journal of Chinese Linguistics, 27, 69-103.

Vertegaal, R., Slagter, R., van der Veer, G., \& Nijholt, A. (2001). Eye gaze patterns in conversations: There is more to conversational agents than meets the eyes. Proceedings of the SIGCHI Conference on Human Factors in Computing Systems (pp. 301-308), ACM (Association for Computing Machinery).

WANG, S. J. (2013). A comparative study of discourse markers in Yang Lan One on One (Unpublished M.A. dissertation, Central China Normal University, Wuhan). 


\section{Appendix A: Transcription Symbols}

[ ] overlap

(0.5) pause length

(.) micropause

, clausal-TCU boundary or continuing intonation

- $\quad$ word cut-off or hesitation

? questioner rising intonation

: $\quad$ prolonged syllable

$=\quad$ latched utterances

/ cooccurrence

${ }^{\circ}$ word $^{\circ} \quad$ softer talk

CAPS louder talk

$<$ word $>\quad$ markedly prolonged talk

$>$ word $<\quad$ markedly rushed talk

() uncertainty about the transcription

(word) best guess of the transcription

((word)) non-verbal cue or transcriber's note

word stress

Appendix B: Glossing Abbreviations

$\begin{array}{ll}\text { ADJ } & \text { adjective marker } \\ \text { CL } & \text { classifier } \\ \text { DC } & \text { declarative } \\ \text { FP } & \text { final particle } \\ \text { GEN } & \text { genitive } \\ \text { MOD } & \text { modifier marker } \\ \text { PL } & \text { plural } \\ \text { PRT } & \text { particle } \\ \text { PST } & \text { past } \\ \text { TP } & \text { topic particle }\end{array}$

